\title{
In vitro proliferation and differentiation of adipose-derived stem cells isolated using anti-CD105 magnetic beads
}

\author{
XIAO-JIE $\mathrm{LV}^{1^{*}}$, GUANG-DONG ZHOU ${ }^{2 *}$, YANG LIU ${ }^{3}$, XIA LIU $^{4}$, \\ JUN-NAN CHEN ${ }^{1}, \mathrm{XU}-\mathrm{SONG} \mathrm{LUO}^{2}$ and YI-LIN CAO ${ }^{2}$ \\ ${ }^{1}$ General Hospital of Second Artillery of PLA, Beijing; ${ }^{2}$ Shanghai Ninth People's Hospital, Shanghai Jiao Tong \\ University School of Medicine, Shanghai; ${ }^{3}$ The 305th Hospital of PLA, Beijing; ${ }^{4}$ Plastic \\ Surgery Hospital, Chinese Academy of Medical Sciences, Beijing, P.R. China
}

Received March 6, 2012; Accepted May 9, 2012

DOI: $10.3892 /$ ijmm.2012.1063

\begin{abstract}
The present study aimed to investigate the feasibility of isolating adipose-derived stem cells (ADSCs) by selecting cells that express the surface receptor CD105. Surface antigen expression of the unsorted cells was undertaken using FACS analysis. Primary adipose-derived cells were isolated. The second passage cells were incubated with anti-CD105 magnetic beads, and separated using a magnetic separator. Cell growth and colony formation was determined by counting and Giemsa staining, respectively. Cells also underwent histological immunohistochemical, and RT-PCR analyses to determine their chondrogenic, adipogenic and osteogenic potential. Increased cell proliferation and colony formation was observed in CD105-positive $\left(\mathrm{CD}_{105^{+}}\right)$as compared to the CD105-negative $\left(\mathrm{CD}_{105}\right)$ cells $(\mathrm{P}<0.001)$. Following induction, the expression of type II collagen and the number of calcium deposits and lipid droplets in the $\mathrm{CD} 105^{+} \mathrm{ADCs}$ were markedly higher than in the CD105- ADCs. Furthermore, increased alkaline phosphatase (AKP), leptin and PPAR $\gamma 2$ mRNA expression was detected in the $\mathrm{CD}_{105^{+}} \mathrm{ADCs}(\mathrm{P}<0.01)$. Isolation of $\mathrm{CD} 105^{+}$ ADSCs by MACS was feasible. Thus, CD105 can be used
\end{abstract}

Correspondence to: Dr Yi-Lin Cao, Shanghai Ninth People's Hospital, No. 639 Zhi Zao Ju Road, Shanghai 200011, P.R. China E-mail: yilincao@yahoo.com

Dr Xiao-Jie Lv, General Hospital of Second Artillery of PLA, No. 16 Xin Jie Kou Wai Street, Beijing 100088, P.R. China

E-mail:1vxiaojie@hotmail.com

"Contributed equally

Abbreviations: ADCs, adipose-derived cells; ADSCs, adiposederived stem cells; AKP, alkaline phosphatase; BMSCs, bone marrow stem cells; CD105-, CD105-negative; CD105+, CD105positive; FBS, fetal bovine serum; H\&E, hematoxylin and eosin; IGF-1, insulin growth factor-1; IBMX, 3-isobutyl-1-methylxanthine; PE, phycoerythrin; SE, standard error; TGF- $\beta 1$, transforming growth factor- $\beta 1$

Key words: adipose-derived stem cell, CD105, immunomagnetic bead, purification, separation as a relatively specific marker for the selection of ADSCs. Although the chondrogenic, adipogenic and osteogenic potential of these cells is suggestive of their potential for use in tissue engineering treatments, further in vivo studies are necessary.

\section{Introduction}

Treatment of tissue defects and injury due to congenital causes, trauma and infection has been one of the challenges for plastic surgeons and trauma surgeons. The rapid development of tissue-engineering techniques provides strategies and potential sources of materials for the repair and regeneration following tissue injury.

The possible use of mesenchymal stem cells (MSCs) for tissue engineering therapies has been increasingly explored. Ideally, MSCs should be autologous, available in sufficient quantity, and easily obtained, with the ability to proliferate and differentiate in vitro (1).

Studies have confirmed the multipotentiality of adiposederived stem cells (ADSCs) $(2,3)$, which have advantages as seed cells for tissue engineering. For example, collection of tissue for ADSC isolation is relatively simple as compared to other sources; human adipose tissue, a rich source of ADSCs, can be obtained by suction-assisted lipectomy (i.e., liposuction) $(4,5)$. This technique is minimally invasive, increasing the likelihood of patient acceptance. However, the chondrogenic potential of ADSCs has come into question (6-8). For example, the maturity and homogeneity of cartilage constructed using ADSCs was lower as compared to that constructed using bone marrow stem cells (BMSCs) (8). This may be attributed to the low proportion of MSCs and the presence of contaminant cells that are likely terminally differentiated.

ADSCs, in fact adipose-derived cells (ADCs), consist of a heterogeneous cell population, including fat precursor cells, hematopoietic cells, endothelial cells, vascular pericytes, and fibroblasts (9). Because some ADCs have directed differentiation and terminally differentiated cells have no chondrogenic potential, the maturity and homogeneity of cartilage is affected. Therefore, separation of ADCs prior to their application is necessary.

The traditional methods employed for separating stem cells include density gradient centrifugation, differential adhe- 
sion, and culturing in serum. However, because these methods are largely nonspecific, the resulting cultures are often of low purity. In addition, these methods are complex, and the experimental period is relatively long. An alternative to the aforementioned methods includes separating the stem cells using stem cell-specific antigens with immunomagnetic beads or flow cytometry. These methods require a short experimental period and result in an increased purity in the stem cell cultures. However, these techniques have yet to be applied to ADSCs due to the lack of a specific surface marker.

To identify a possible ADSC-specific surface antigen, ADCs were analyzed for the expression of commonly used MSC-related antigens, including endoglin (CD105), CD166 (activated leukocyte cell adhesion molecule, ALCAM) and STRO-1. In the present study, CD105, a relatively specific antigen for MSCs, was applied for the separation of ADSCs. $\mathrm{CD} 105^{+}$and $\mathrm{CD}^{-} 05^{-} \mathrm{ADC}$ growth, colony formation, and differentiation potentials were assessed. These findings provide theoretical and practical evidence for the separation and purification of ADSCs.

\section{Materials and methods}

Isolation and culture of ADCs. Adipose tissues were collected from patients receiving suction lipectomy in the Department of Plastic Surgery, Ninth People's Hospital, Shanghai Jiao Tong University School of Medicine. Of the 5 patients, 4 were female; the mean age was 28.5 years (range, $22-45$ years), and the lipectomy sites were abdomen $(n=2)$ and thigh $(n=3)$.

The adipose tissues from five patients were separately washed twice in PBS and then digested in $0.075 \%$ collagenase NB4 (Serva, Heidelberg, Germany) for $1 \mathrm{~h}$ followed by centrifugation at 1,380 rpm for $10 \mathrm{~min}$. The cell sediments were collected and resuspended in DMEM (Gibco, Grand Island, NY, USA) supplemented with $10 \%$ fetal bovine serum (FBS; Hyclone Labs, Thermo Scientific, Rockford, IL, USA). The cell density was adjusted to $4 \times 10^{5}$ cells $/ \mathrm{cm}^{2}$, and the ADCs were seeded into disks followed by culture and passaging. ADCs in the second passage were used for subsequent experiments.

Identification of surface antigens on the ADCs. Analysis of surface antigen expression was undertaken in ADCs of the first and second passage using flow cytometry. Cells were digested in $0.25 \%$ trypsin and $0.02 \%$ EDTA (Sigma, St. Louis, MO, USA), collected, and isolated by centrifugation at $1,500 \mathrm{rpm}$ for $5 \mathrm{~min}$. The cell density was adjusted to $0.5 \times 10^{6} \mathrm{cells} / \mathrm{ml}$, and $1 \mathrm{ml}$ of the cell suspension was added into a 1.5-ml Eppendorf tube followed by centrifugation at $1,500 \mathrm{rpm}$ for $5 \mathrm{~min}$. After the supernatant was removed, the ADCs were resuspended in $100 \mu \mathrm{l}$ of $1 \% \mathrm{BSA}$ after which they were treated with the following primary antibodies diluted $1: 50$ at $4^{\circ} \mathrm{C}$ : integrin $\beta 1 /$ CD29 (sc8978; Santa Cruz Biotechnology, Inc., Santa Cruz, CA, USA), integrin $\alpha 4 / C D 49 d$ (9431-09A; Southern Biotech, Birmingham, AL, USA), ALCAM/CD166 (MCA1926F; AbD Serotec), PECAM-1/CD31 (F-8402; Sigma), hematopoietic/ CD34 (M0824; Dako, Carpinteria, CA, USA), CD14 (T5647; Sigma), endoglin/CD105 (MCA1557PE; AbD Serotec, Raleigh, NC, USA), VCAM-1/CD106 (sc13160) and VEGFR-2/ FLK-1 (sc505) (Santa Cruz Biotechnology, Inc.), and STRO-1 (MAB1038; R\&D Systems, Minneapolis, MN, USA). After
30 min, ADCs were separated by centrifugation, washed in PBS, and treated with goat anti-mouse IgM-FITC secondary antibody (AMI3608; Biosource, Carlsbad, CA, USA) diluted $1: 200$ at $4^{\circ} \mathrm{C}$ for $30 \mathrm{~min}$. After the cells were fixed in $10 \%$ formalin, they were subjected to flow cytometry. Control groups consisted of an isotype control group and blank control group. Each experiment was performed 5 times and the averages were obtained.

Separation of ADCs using anti-CD105 magnetic beads and $M A C S$. ADCs in their second passage were digested in $0.25 \%$ trypsin $+0.02 \%$ EDTA and centrifuged at $1,500 \mathrm{rpm}$ for $5 \mathrm{~min}$. The cell density was adjusted to $0.5 \times 10^{6}$ cells $/ \mathrm{ml}$, and $10 \mathrm{ml}$ was added to a $15-\mathrm{ml}$ centrifuge tube followed by centrifugation at 1,500 rpm for $5 \mathrm{~min}$. The cells were resuspended in $1 \mathrm{ml}$ of $1 \%$ BSA and treated with CD105 conjugated to phycoerythrin (PE; AbD Serotec, Oxford, UK) diluted 1:50 at $4^{\circ} \mathrm{C}$ for $30 \mathrm{~min}$ followed by centrifugation at $1,500 \mathrm{rpm}$ for $5 \mathrm{~min}$. After washing in PBS, the cells were centrifuged at 1,500 rpm for $5 \mathrm{~min}$, and resuspended in $1 \mathrm{ml}$ of $1 \% \mathrm{BSA}$, and incubated with anti-PE magnetic beads (Miltenyi Biotec, Auburn, CA, USA) diluted $1: 50$ at $4^{\circ} \mathrm{C}$ for $30 \mathrm{~min}$. After centrifugation (1,500 rpm, $5 \mathrm{~min})$, the cells were washed in PBS, centrifuged, at 1,500 rpm for $5 \mathrm{~min}$, and resuspended in $1 \mathrm{ml}$ of $1 \%$ BSA. The remaining cells were prepared for separation by MACS.

CD105-conjugated ADCs were separated using autoMACS (Miltenyi Biotec). CD105+ and CD105- ADCs were collected into aseptic 15-ml centrifuge tubes. The double-positive and double-negative modes were employed to achieve pure $\mathrm{CD} 105^{+}$ and $\mathrm{CD} 105^{-} \mathrm{ADCs}$, respectively. The isolated cells were seeded onto five $100-\mathrm{mm}$ disks at a density of $1 \times 10^{4}$ cells $/ \mathrm{cm}^{2}$ for the following experiments. Flow cytometry was used to measure the purities of $\mathrm{CD} 105^{+}$and $\mathrm{CD} 105^{-} \mathrm{ADCs}$; $0.5 \times 10^{6}$ cells

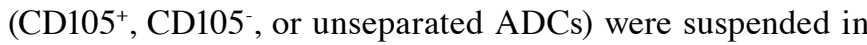
$100 \mu \mathrm{l}$ of $1 \%$ BSA and subjected to flow cytometry using the methods described above.

Analysis of cell growth and colony formation. $\mathrm{CD} 105^{+}$and CD105- ADC growth and colony formation was determined by cell counting and Giemsa staining (Shanghai Chemical Reagents Co., Ltd., Shanghai, China), respectively. The growth kinetics of $\mathrm{CD} 105^{+} \mathrm{ADCs}$ were compared with that of CD105- ADCs.

Analysis of ADC differentiation potential. The differentiation potentials of the following cell groups were determined: induced $\mathrm{CD}_{105}{ }^{+} \mathrm{ADCs}$, non-induced $\mathrm{CD}_{105^{+}} \mathrm{ADCs}$, induced CD105- ADCs, and non-induced CD105- ADCs. Each experiment was independently repeated 6 times.

For chondrogenetic induction cells $\left(2.5 \times 10^{5}\right)$ were induced with $5 \mathrm{ml}$ of chondrogenetic induction medium containing $10 \mu \mathrm{g}$ transformation growth factor- $\beta 1$ (TGF- $\beta 1)$ (R\&D Systems), $50 \mu \mathrm{g}$ insulin growth factor-1 (IGF-1) (R\&D Systems), and $2 \mathrm{mg} / \mathrm{ml}$ dexamethasone (Sigma) followed by centrifugation at $1380 \mathrm{rpm}$ for $5 \mathrm{~min}$. The cell pellets were maintained in the chondrogenetic induction medium for 14 and 21 days. In the non-induced groups, the medium was replaced with DMEM alone.

For osteogenic induction the cells were digested and seeded onto a 24 -well plate at a density of $1 \times 10^{4}$ cells/well. 
Table I. Reverse transcriptase-polymerase chain reaction (RT-PCR) primers.

\begin{tabular}{lrr}
\hline Gene (product size) & \multicolumn{1}{c}{ Sense } & \multicolumn{1}{c}{ Antisense } \\
\hline PPAR $\gamma(493 \mathrm{bp})$ & 5'-GATCCAGTGGTTGCAGATTA-3' & 5'-GGTCAGCGGGAAGGACTTTA-3' \\
COLII (510 bp) & 5'-TCCCCGGCACTCCTGGCACTGAT-3' & 5'-CTTGGGCACCTCGGGCTCCTTTAG-3' \\
AKP (467 bp) & 5'-CTGGTAGGCGATGTCCTTA-3' & 5'-ACGTGGCTAAGAATGTCATC-3' \\
Leptin (481 bp) & 5'-CAAGCTGTGCCCATCCAAAA-3' & 5'-GCCAGAGTTCCTTCCCTTAA-3' \\
$\beta$-actin (318 bp) & 5'-ATCATGTTTGAGACCTTCAA-3' & 5'-CATCTCTTGCTCGAAGTCCA-3'
\end{tabular}

For induction, cells were maintained in osteogenic induction medium containing $10 \mathrm{nM}$ vitamin D3 (Sigma) and $10 \mathrm{mM}$ $\beta$-phosphoglycerol (ICN Biomedicals, Solon, OH, USA) and $0.1 \mu \mathrm{M}$ dexamethasone for 14 and 21 days, and those in the non-induced groups were cultured in traditional DMEM.

For adipogenic induction the cells were digested and seeded onto a 24 -well plate at a density of $1 \times 10^{4}$ cells/well. When cell confluence reached $80 \%$, cells in the induced groups were maintained in the adipogenic induction medium containing $0.5 \mathrm{mM}$ 3-isobutyl-1-methylxanthine (IBMX), $200 \mu \mathrm{M}$ indomethacin, $10 \mu \mathrm{M}$ insulin and $1 \mu \mathrm{M}$ dexamethasone (all from Sigma) for 14 and 21 days; those in the non-induced groups were cultured in traditional DMEM.

Immunohistochemistry analysis. As previously described in Liu et al (10), the cells were fixed in $10 \%$ formalin, embedded in paraffin, and sectioned into 5- $\mu \mathrm{m}$ slices. The sections were stained with hematoxylin and eosin (H\&E) to evaluate histological structure. Analysis of collagen II expression was performed by $1 \%$ BSA blocked sections using 1:100 mouse anti-human type II collagen monoclonal primary antibody (Dako) at $4^{\circ} \mathrm{C}$ overnight, followed by 1:200 horseradish peroxidase (HRP)-conjugated goat anti-mouse secondary antibody (Dako) at $37^{\circ} \mathrm{C}$ for $30 \mathrm{~min}$. DAB was used as a substrate for HRP.

Alizarn Red and Oil Red staining was performed respectively to evaluate the formation of calcium deposits and lipid droplet.

Reverse-transcriptase polymerase chain reaction (RT-PCR) analysis. Total-RNA was extracted from the cells after multilineage induction using TRIzol (Invitrogen, CA). cDNA was obtained using previously described methods (11). RT-PCR was performed with different primers respectively. $\beta$-actin mRNA expression was quantified as an internal control. The primer sequences for each gene analyzed are listed in Table I.

Statistical analysis. Cell growth is presented as mean \pm standard error (SE). Mean cell number over time were compared through repeated ANOVA measurements. Two-sample t-test at each time-point was performed to compare the differences between $\mathrm{CD} 105^{-} \mathrm{ADCs}$ and $\mathrm{CD} 105^{+} \mathrm{ADCs}$. Colony formation rates are presented as bar graphs, representing the mean $\pm \mathrm{SE}$ and compared using two-sample t-tests. Collagen II, alkaline phosphatase (AKP), leptin, and PPAR $\gamma 2$ mRNA expression was presented as bar graphs, representing mean \pm SE. Data among four conditions $\left(\mathrm{CD} 105^{+}\right.$induced and non-induced and $\mathrm{CD} 105^{-}$induced and non-induced) were compared using one-way ANOVA with Bonferroni adjustment. Data withinconditions (change from Day 14-21) were compared using paired t-tests. All statistical assessments were two-tailed, and $\mathrm{P}<0.05$ was considered significant. Statistical analyses were performed using the SPSS 15.0 statistics software (SPSS Inc., Chicago, IL, USA).

\section{Results}

ADC surface antigen expression. To determine which surface antigen may be useful for isolation of ADSCs from a mixed ADC population, ADCs in the first and second passage were analyzed for various stem cell-associated surface antigens. First passage ADCs were largely negative for CD14, CD106, STRO-1, and Flk-1 but positive for CD29, CD31, CD34, CD49d, CD105 and CD166 (Table II). ADCs in the second passage had significantly decreased CD34 expression and were negative for CD31 and CD49d but positive for CD14, STRO-1 and Flk-1. In the second passage, the expressions of CD14, CD105, CD166, STRO-1, and Flk-1 were markedly higher than observed in the first passage (Table II).

Inverted phase contrast microscopy was employed to observe the morphology of ADCs in the first and second passage as well as after separation (Fig. 1). The first passage ADCs consisted of different types of cells with diverse morphologies, including short-spindle shape, spindle shape, and flat shaped cells (Fig. 1, left panel). The second passage cells were largely spindle shaped (Fig. 1, right panel).

Cell growth and morphology of ADCs separated by CD105. Prior to separation by CD105, 30\% of ADCs were positive for CD105. After enrichment for CD105 expression, the proportion of $\mathrm{CD}_{105^{+}}$cells was increased to $90 \%$, suggesting that MACS successfully enriched $\mathrm{CD} 105^{+}$(Fig. 2A). After separation, $<5 \%$ of the $\mathrm{CD} 105$ population was positive for $\mathrm{CD} 105$ (Fig. 2A).

After separation, the morphology of CD105- ADCs was fibroblast-like, and their growth was directional, reaching near $100 \%$ confluence after five to 6 days of culture (Fig. 2B, left panel). The growth of $\mathrm{CD} 105^{+} \mathrm{ADCs}$ was relatively slow and was characterized by clone-like growth; near $100 \%$ confluence was reached after 6-7 days. $\mathrm{CD} 105^{+} \mathrm{ADCs}$ were largely long-spindle shaped with a fraction of cells that were shortspindle shaped, small-round or long-narrow-shaped (Fig. 2B, right panel). 

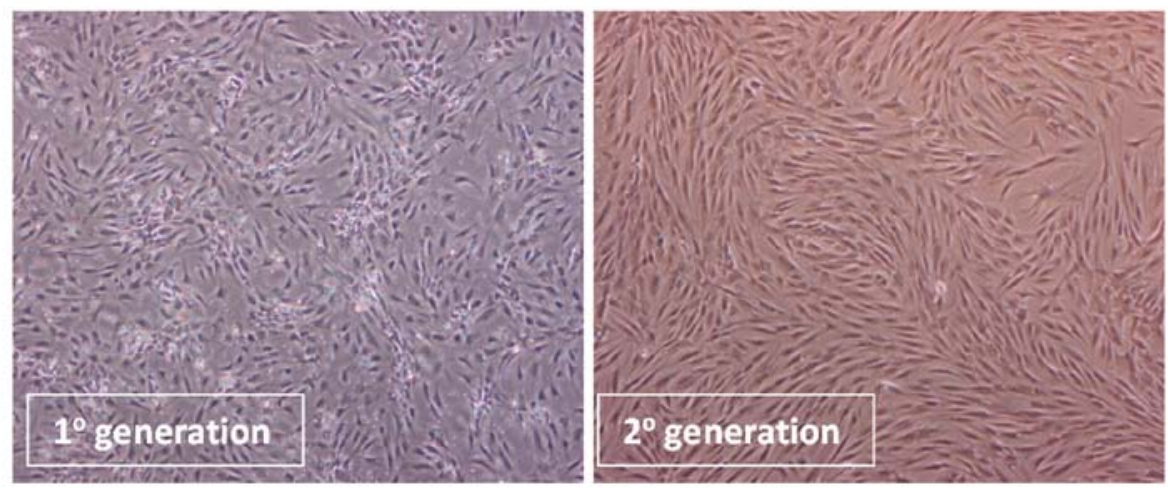

Figure 1. Morphology of ADCs in the first and second passage.

Table II. Stem-cell antigen expression in ADCs.

\begin{tabular}{lccr}
\hline Antigen & First generation $(\%)$ & Second generation $(\%)$ & P-value $^{\mathrm{a}}$ \\
\hline CD14 & $2.99 \pm 0.4$ & $7.98 \pm 0.78$ & 0.009 \\
CD29 & $82.03 \pm 3.4$ & $64.26 \pm 2.49$ & 0.025 \\
CD31 & $15.12 \pm 1.24$ & $2.69 \pm 0.5$ & 0.001 \\
CD34 & $20.99 \pm 1.84$ & $6.02 \pm 0.56$ & 0.001 \\
CD49d & $14.8 \pm 0.84$ & $1.29 \pm 0.23$ & $<0.001$ \\
CD105 & $20.71 \pm 2.08$ & $35.33 \pm 1.6$ & 0.002 \\
CD106 & $4.49 \pm 0.34$ & $0.42 \pm 0.09$ & 0.001 \\
CD166 & $18.98 \pm 0.93$ & $62.41 \pm 2.35$ & $<0.001$ \\
Flk-1 & $2.24 \pm 0.21$ & $9.42 \pm 0.87$ & 0.001 \\
STRO-1 & $3.41 \pm 0.18$ & $10.55 \pm 0.99$ & 0.002 \\
\hline
\end{tabular}

Data were summarized as mean \pm SE and compared between first and second generation using paired t-test. ${ }^{\mathrm{a}} \mathrm{P}<0.05$.

CD105 ${ }^{+}$and $\mathrm{CD} 105^{-}$ADC growth was characterized by rapid growth after 3-4 days. CD $105^{+} \mathrm{ADCs}$ growth was continuous without a plateau. However, CD105- ADC growth was suppressed after 6 days with a doubling time of $72 \mathrm{~h}$ (Fig. 2C).

CD105 ${ }^{+}$cell colony formation. Colony formation was assessed in both $\mathrm{CD} 105^{+}$and CD105 cells (Fig. 3). After two weeks, single cell-derived colonies were observed, consisting of 50-100 cells. Cells within the colonies were long-spindle shaped, short-spindle shaped, small-round or long-narrow shaped (Fig. 3A). CD105+ ADC colonies enlarged gradually; the growth of CD105 ADCs was slow, with some aging. After three weeks, Giemsa staining revealed significantly larger $\mathrm{CD}_{105^{+}} \mathrm{ADC}$ colonies as compared to $\mathrm{CD} 105^{-} \mathrm{ADCs}$ $(\mathrm{P}<0.001)$ with diameters up to $1.5 \mathrm{~cm}$ (Fig. 3B and C).

Differentiation potentials of $\mathrm{CD} 105^{+}$and $\mathrm{CD} 105^{-} \mathrm{ADCs}$. The potential for $\mathrm{CD}_{105^{+}}$. ADCs to differentiate into cartilage, bone and adipose tissue was assessed. At 14 days after chondrogenetic induction, a round, pale, smooth, elastic mass was observed (Fig. 4A). The mass observed from induced $\mathrm{CD} 105^{+}$ ADC (Fig. 4A, group 1) was larger and more elastic than those derived from induced CD105- ADCs (Fig. 4A, group 3). In the non-induced groups (Fig. 4A, groups 2 and 4), the cells were irregular, grey, soft and non-elastic. Collagen II expression was observed in both induced groups; however, $\mathrm{CD} 105^{+}$ ADCs had significantly greater collagen II expression as compared to CD105- ADCs on Days 14 and 21 (Figs. 4B and C and $7 \mathrm{~A})(\mathrm{P}<0.001)$. Collagen II expression was significantly increased in both induced groups from Days 14-21 $(\mathrm{P}<0.05)$. Both non-induced groups were negative for type II collagen (Fig. 4B and C).

Seven days after osteogenic induction, the long spindleshaped cells became flat, and had flake-like growth, which was similar to osteocytes (Fig. 5A, groups 1 and 3). Fourteen days after osteogenic induction, dark brown nodule-like deposits were found to be sporadic. The number and volume of deposits were larger in $\mathrm{CD} 105^{+} \mathrm{ADCs}$; no obvious changes in cell morphology were found in the non-induced groups (Fig. 5A, groups 2 and 4). Alizarin Red staining showed red, nodule-like calcium deposits in the induced groups, which were not found in the non-induced groups (Fig. 5B). AKP expression was observed in both induced groups; however, it was significantly higher in the induced $\mathrm{CD} 105^{+} \mathrm{ADCs}$ as compared to induced CD105 ADCs $(\mathrm{P}<0.05)$ (Figs. 5C and 7B). AKP expression was significantly decreased in both induced groups from Days 14-21 $(\mathrm{P}<0.001)$. 
A

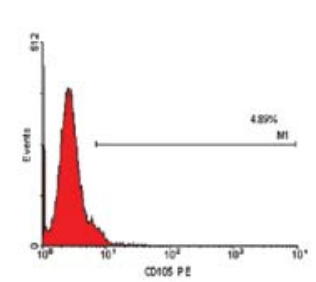

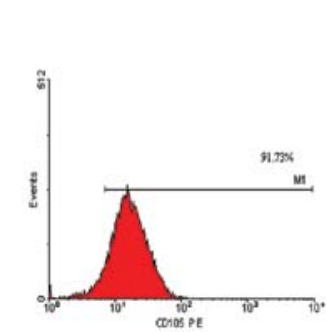
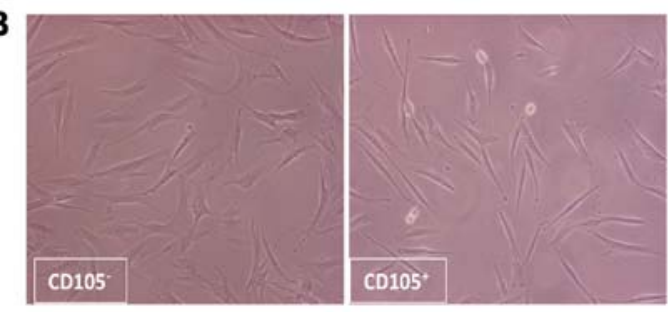

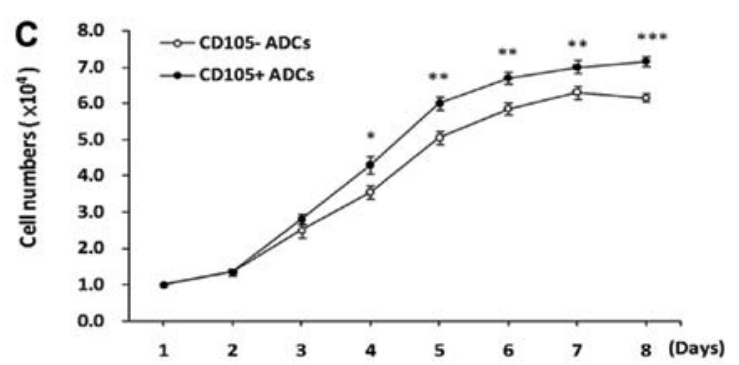

Figure 2. $\mathrm{CD} 105^{+} \mathrm{ADC}$ purity, morphology and growth. (A) Cell purity after magnetic sorting was assessed by FACS analysis. left: CD105, right: CD105+. (B) Morphology of CD105 and CD105+ ADCs was determined using inverted phase contract microscopy. (C) Cell growth was assessed over an 8-day period. The cell numbers were presented as mean $\pm \mathrm{SE}$. ${ }^{*} \mathrm{P}<0.05,{ }^{* *} \mathrm{P}<0.01$ and ${ }^{* * *} \mathrm{P}<0.001$.
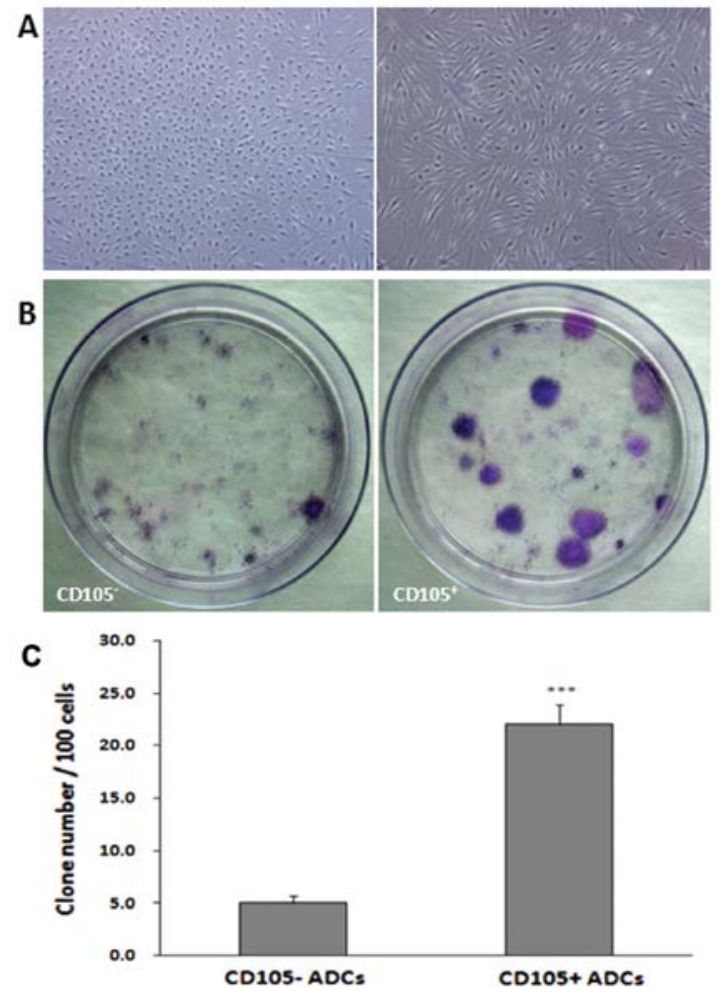

Figure 3. $\mathrm{CD} 105^{+} \mathrm{ADC}$ colony formation and morphology. (A) Clone morphology of sorted ADCs revealed at least two distinct clones: 'round and small' or 'long stretched' shapes. (B) Colony formation was assessed using Giemsa staining. (C) Colony formation rate is presented as mean $\pm \mathrm{SE}$ and compared using two-sample t-test. ${ }^{* * *} \mathrm{P}<0.001$.

At 3 days after adipogenic induction, both $\mathrm{CD} 105^{+}$and $\mathrm{CD} 105^{-}$cells transformed from long spindle-shaped to roundlike. Seven days after induction, cell growth became slow, and the morphology was also altered; small lipid droplets were found in the cytoplasm; near mature adipocytes were observed after 14 days (Fig. 6A, groups 1 and 3). The number of adipocytes and lipid droplets was higher in the $\mathrm{CD} 105^{+} \mathrm{ADC}$ group
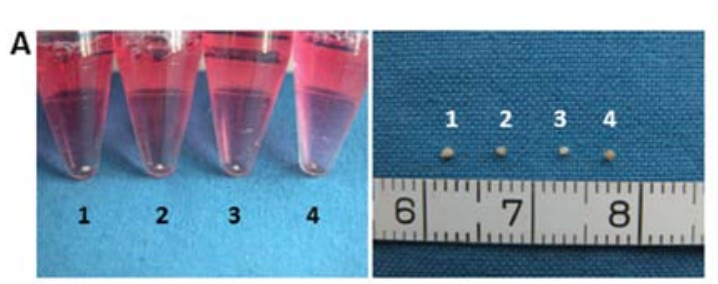

B
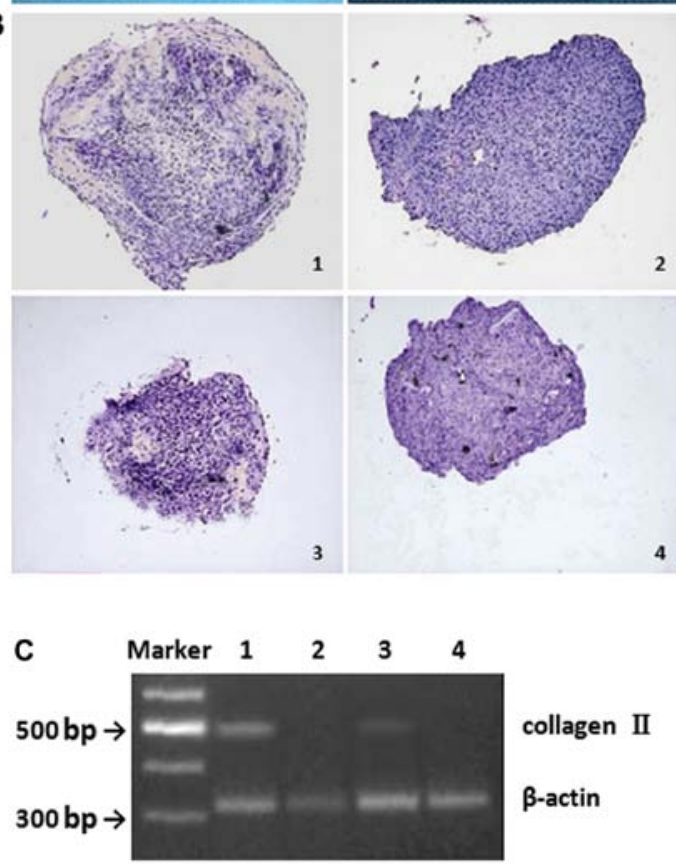

Figure 4. Chondrogenic differentiation of $\mathrm{CD} 105^{+}$ADCs. (A) Gross examination of $\mathrm{CD} 105^{+}$cells after being induced for chondrogenic differentiation for 14 days. (B) Type II collagen protein and (C) mRNA expression was determined by immunohistochemistry and RT-PCR, respectively. Lane 1, CD105 ${ }^{+}$ induced; lane 2, CD105/non-induced; lane 3, CD105/induced; and lane 4, CD105\% non-induced.

than in the CD105- $\mathrm{ADC}$ group. No obvious changes were observed in the non-induced groups (Fig. 6A, groups 2 and 4). Oil Red staining revealed lipid-containing cytoplasms in 

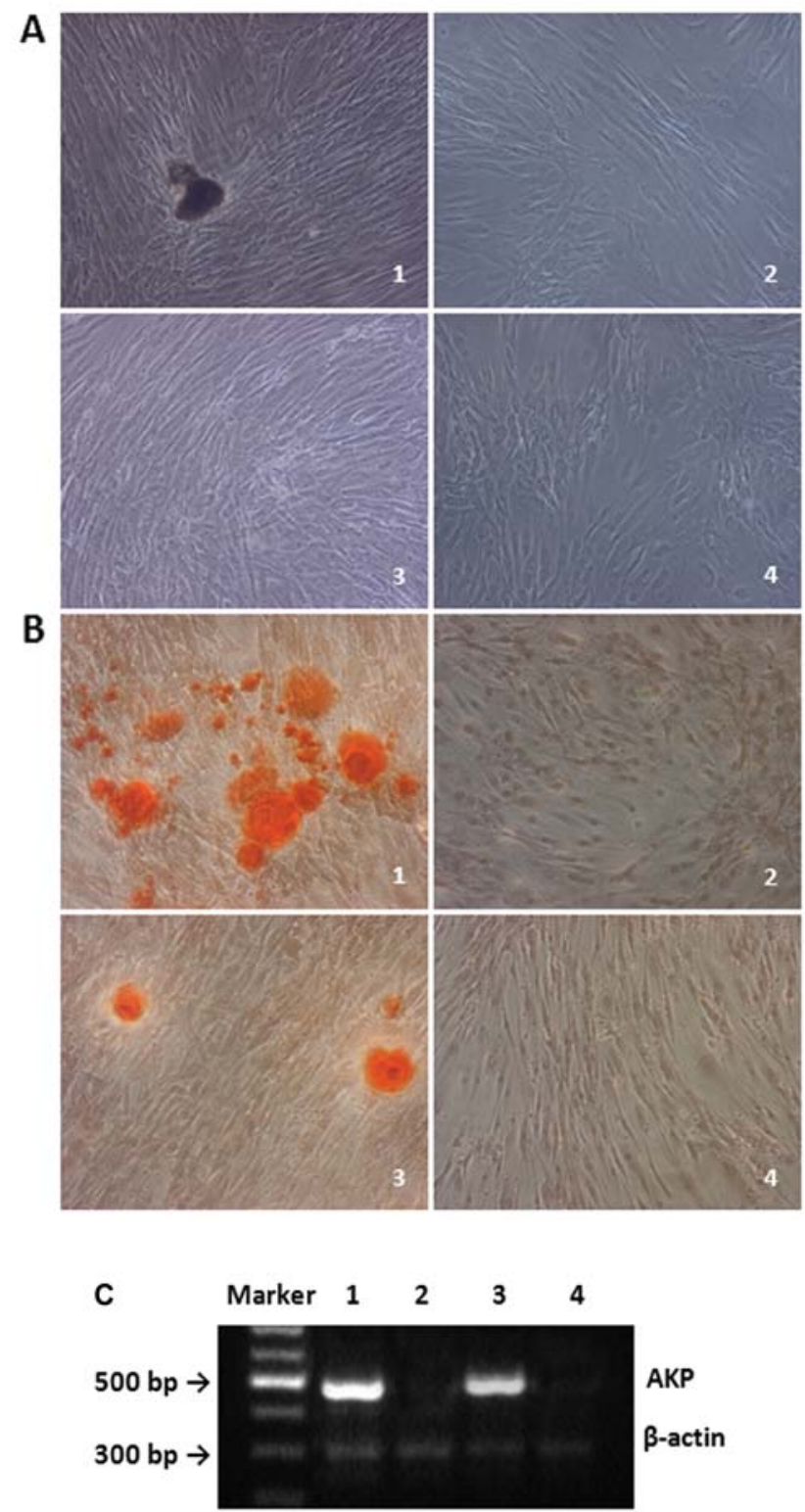

Figure 5. Osteogenic differentiation of $\mathrm{CD} 105^{+} \mathrm{ADCs}$. Osteogenic differentiation of $\mathrm{CD} 105^{+} \mathrm{ADCs}$ after induction for 21 days was visualized using light microscopy (A) without and (B) with Alizarn Red staining. (C) AKP mRNA expression was evaluated by RT-PCR analysis as a molecular marker for osteogenic differentiation. Lane 1, CD105/induced; lane 2, CD105/noninduced; lane 3, CD105/induced; and lane 4, CD105\%/non-induced.

induced cells, which were absent in the non-induced groups (Fig. 6B). Increased leptin and PPAR $\gamma 2$ expression was observed in both induced groups; their expression was negative in both non-induced groups (Fig. 6C). Induced CD105 ${ }^{+}$ ADCs expressed significantly greater leptin and PPAR $\gamma 2$ expression as compared to induced CD105-ADCs $(\mathrm{P}<0.01)$ (Fig. 7C and D). Leptin and PPAR $\gamma 2$ expression was significantly increased in both induced groups from Days 14-21 $(\mathrm{P}<0.05)$.

\section{Discussion}

Although the advantages of ADSCs (i.e., simple collection and high yield) are apparent, the maturity and homogeneity of cartilages constructed using ADSCs were inferior to those
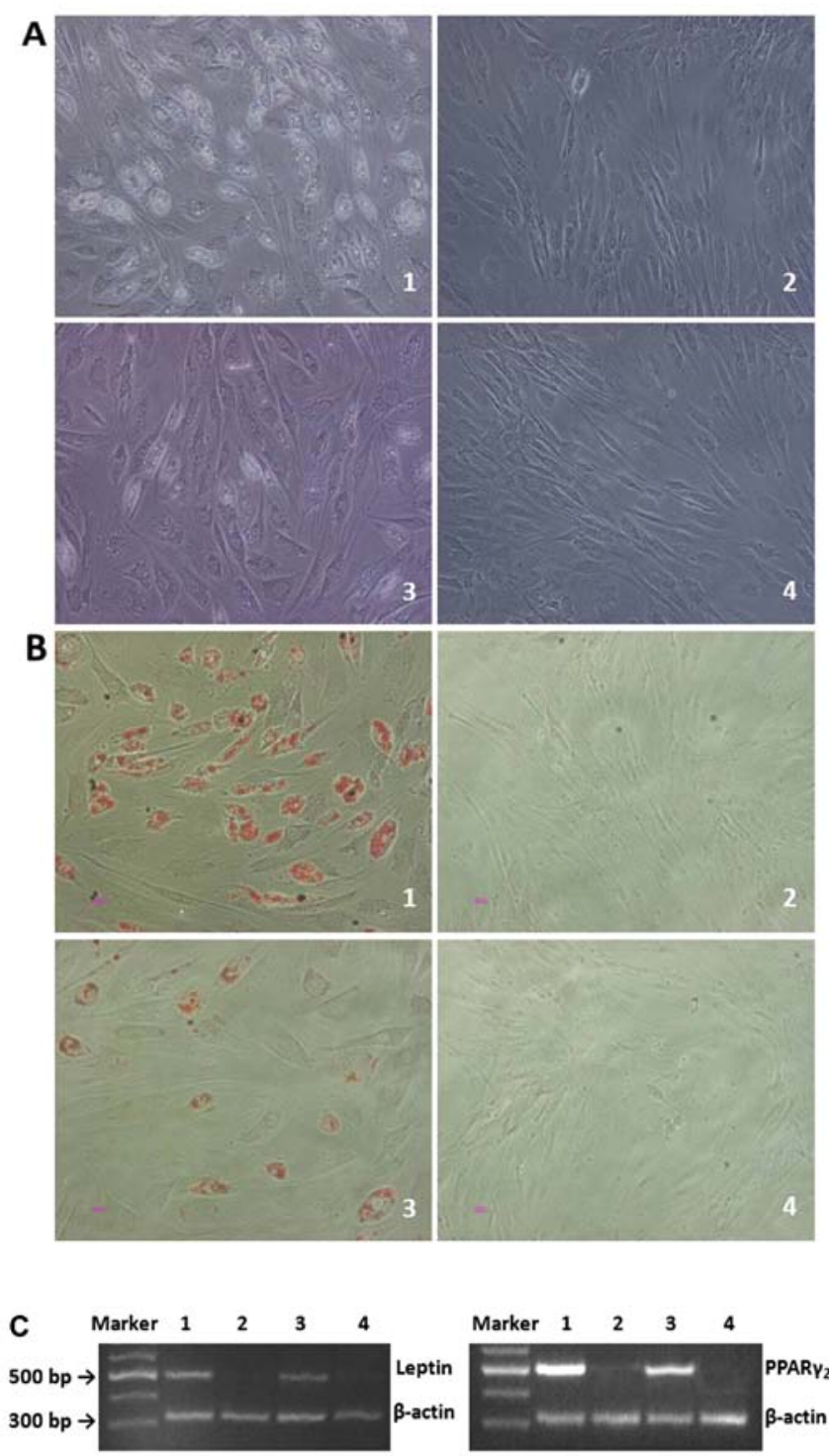

Figure 6. Adipogenic differentiation of $\mathrm{CD} 105^{+} \mathrm{ADCs}$. Adipogenic differentiation of $\mathrm{CD} 105^{+} \mathrm{ADCs}$ after induction for 14 days was visualized using light microscopy (A) without and (B) with Oil Red staining. (C) Leptin and PPAR $\gamma 2$ mRNA analysis was assessed by RT-PCR as molecular markers for adipogenic differentiation. Lane 1, CD105/induced; lane 2, CD105+/noninduced; lane 3, CD105/induced; and lane 4, CD105\%/non-induced.

using BMSCs (8). This may be attributed to the low proportion of MSCs in the isolated ADSCs. In an effort to isolate ADSCs from a mixed-cell ADC population isolated using suction-assisted lipectomy, ADCs were separated based upon CD105 surface expression. CD105 ${ }^{+}$ADCs displayed increased cell proliferation and colony formation as compared to the CD105- cells. Upon induction, CD105 ${ }^{+}$ADCs differentiated into chondrocytes, osteocytes, and adipocytes to a greater extent than that observed for $\mathrm{CD} 105^{-} \mathrm{ADCs}$, which is similar to other reports demonstrating their ability to differentiate into chondrocytes (8), osteoblasts (12), endothelial cells (13), muscle cells $(14,15)$, and even hepatocytes (16).

Because culturing can change the expression of ADSCs in mice (17), ADCs in the first and second passage were analyzed for various stem cell-associated surface antigens to determine which surface antigen may be useful for isolation of ADSCs. Mitchell et al (18) similarly investigated the surface markers 
A
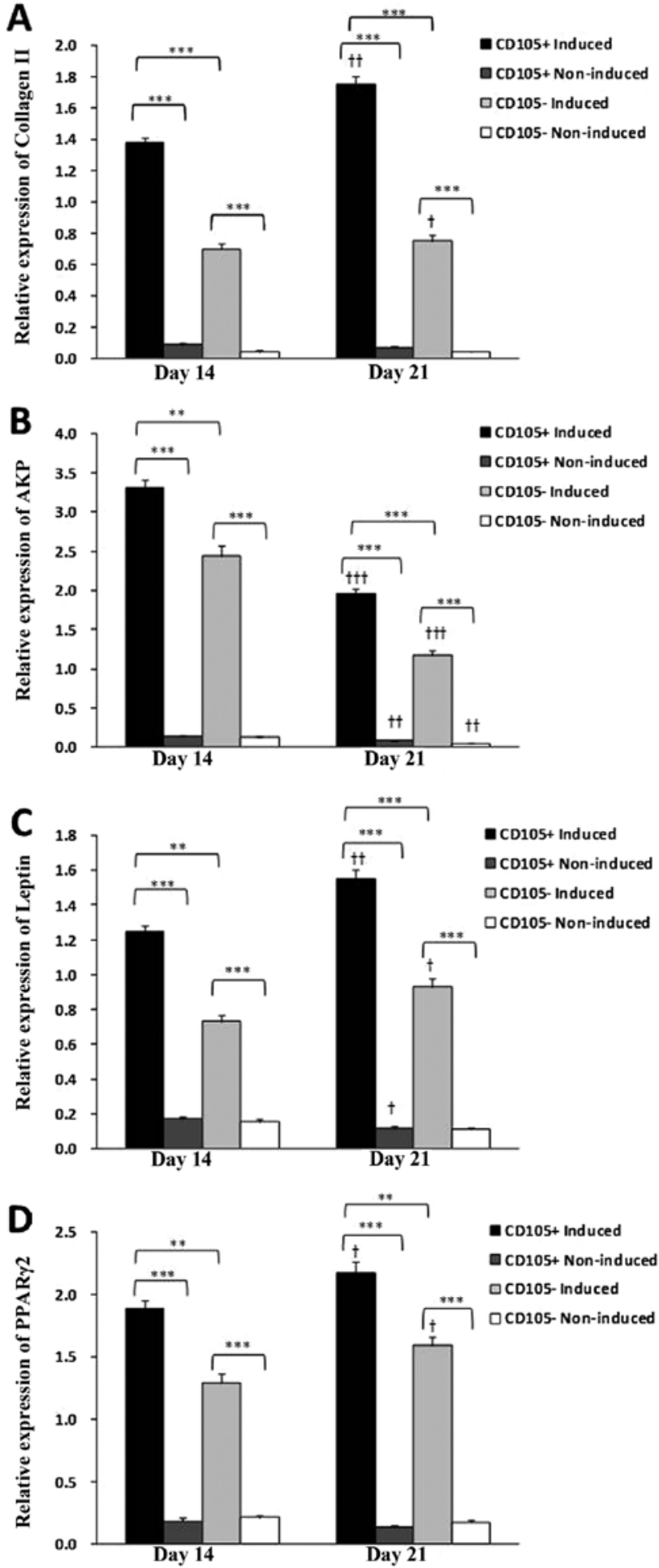

Figure 7. Expression of differentiation markers on induced CD105 ${ }^{+} \mathrm{ADCs}$ (A) Collagen II, (B) AKP, (C) leptin, and (D) PPAR $\gamma 2$ mRNA expression was determined in $\mathrm{CD}_{105^{+}}$and $\mathrm{CD} 105^{-} \mathrm{ADCs}$ with or without differentiationinducing reagents. Data were presented as mean $\pm \mathrm{SE}$. ${ }^{*} \mathrm{P}<0.05,{ }^{* *} \mathrm{P}<0.01$ and ${ }^{* * *} \mathrm{P}<0.001$ indicated significantly different among conditions. Significant changes from Days 14-21 were indicated using the following: ${ }^{\top} \mathrm{P}<0.05$, ${ }^{\dagger} \mathrm{P}<0.01$ and ${ }^{\dagger+} \mathrm{P}<0.001$.

on cells obtained from fat aspirates; the surface markers on these cells included CD13, CD29, CD44, CD63, CD73, CD90, CD105 and CD166, which were similar to those observed on BMSCs. The expression of these markers, including CD49D, CD44, CD90, CD105, CD13 and CD71 were stable for up to
7 passages and 3 months in culture (19). Izadpanah et al (20) proposed that both ADSCs and BMSCs were positive for the embryonic stem cell antigens, Oct-4, Rex-1 and Sox-2. In the present study, ADCs were positive for the MSC-related surface antigens, CD105, CD166 and STRO-1; the percentage of cells expressing these markers increased from the first to the second passage. In addition, ADCs expressed hematopoietic and endothelial cell-related surface antigens, including CD34 and CD31. These findings suggest that ADCs contain MSCs as well as contaminant cells and possibly other non-MSCs.

To address the need for a simple method of obtaining and purifying ADSCs from a mixed ADC population, we employed an immunomagnetic bead assay with MACS similar as in Jiang et al (21). Griesche et al (22) compared the various methods of obtaining homogeneous MSC populations from adipose tissue, reporting a minor advantage of using immunomagnetic isolation with the disadvantage of lower yeild. Because the proportion of $\mathrm{CD} 105^{+}$cells was relatively stable between the first and second passages, it was selected as the marker for separation; the proportion of $\mathrm{CD}_{105^{+}}$cells was $>90 \%$ after separation, which is similar to that obtained using FACS (21). Thus, separation of ADCs using the immunomagnetic bead assay can achieve a target cell population of high purity.

CD105 is a relatively specific marker for MSCs. Within a population of BMSCs, $\mathrm{CD} 105^{+}$cells have been shown to exhibit stronger stemness as compared to CD105- cells (23). In addition, $\mathrm{CD} 105^{+}$cells isolated from human (24) and rat (25) synovial fluid, human bone marrow (26) as well as mouse adipose-derived vascular fraction (27) have been reported to exhibit strong chondrogenic potential.

To determine whether the separated cells had the characteristics of stem cells, their morphology, self-renewal capacity, and multipotentiality were assessed. $\mathrm{CD} 105^{+} \mathrm{ADCs}$ were largely long spindle-shaped with a small fraction of cells being short spindle-shaped, small round, and long narrow-shaped. The majority of CD105-ADCs were long spindle-shaped with few processes; they were also larger. In addition, large $(>1 \mathrm{~cm})$ colonies were observed from the $\mathrm{CD} 105^{+} \mathrm{ADCs}$ after 3 weeks. Few single-cell colonies were found in $\mathrm{CD}^{-} 05^{-} \mathrm{ADCs}$; the majority did not grow due to the presence of aging cells, suggesting that the CD105- ADC population contained differentiated cells. Furthermore, $\mathrm{CD} 105^{+} \mathrm{ADCs}$ displayed significantly greater proliferation as compared to CD105- ADCs. These results differ from those published by Jiang et al (21). In their study ADCs were separated based upon CD105 expression using FACS analysis; no differences in proliferation or colony formation were noted. This may be caused by differences in the tissue source, culture condition, and most importantly the separation methods. Using magnetic beads might improve the purity of the isolated cells, but parallel experiments of these 2 methods should be performed to prove this hypothesis.

The adipogenic, osteogenic, and chondrogenetic potentials of the $\mathrm{CD} 105^{+}$cells were confirmed. Dramatic differences in the chondrogenetic and osteogenic potentials were observed between the $\mathrm{CD} 105^{+}$and $\mathrm{CD} 105^{-} \mathrm{ADCs}$, which is similar to that observed by Jiang et al (21). Specifically, lacuna-like structures were rarely found in cell micromass of CD105 ADCs, and the amount of type II collagen was relatively small. Differences in the adipogenic potential were relatively small 
between the two cell populations, which may be attributed to the presence of fat precursor cells in the CD105- ADCs. Because the differentiation potential of MSCs is mainly reflected in their chondrogenetic and osteogenic potentials, we speculate that the proportion of MSCs in the CD105+ ADC population is higher than that in CD105- ADCs. The limited chondrogenetic and osteogenic potential observed for the CD105- cells may be due to the following: i) a fraction of $\mathrm{CD} 105^{+}$cells were present in the $\mathrm{CD} 105^{-}$cell population; ii) not all ADC-derived MSCs express CD105, and ADSCs may consist of different cell types; and iii) the presence of precursor cells, such as fat precursor cells, precursor chondroblasts and precursor osteoblasts, in the CD105- ADCs cannot be ruled out. However, further studies are required to determine the therapeutic efficacy of using the $\mathrm{CD} 105^{+} \mathrm{ADC}$ population for tissue engineering.

The mechanism by which CD105 promotes MSC chondrogenesis has yet to be determined. It is a member of the TGF- $\beta$ receptor superfamily, that binds to TGF- $\beta 1$ and TGF- $\beta 3$ by associating with the TGF- $\beta$ type II receptor and modulating cellular responses to TGF- $\beta$ (28). Therefore, CD105 may mediate TGF- $\beta$-induced chondrogenesis $(29,30)$. However, further studies are necessary to determine the mechanism by which CD105 influences MSC chondrogenesis.

The present study has its limitations. Firstly, isolated ADSCs differentiated into chondrocytes, osteocytes, and adipocytes all of which are mesodermal in origin. The capability these isolated cells to differentiate to other germ layers needs further analysis. Also, the differentiation potentials of these cells was only assessed using in vitro studies; therefore, further in vivo studies are necessary to confirm their utility for tissue engineering purposes.

In conclusion, $\mathrm{CD} 105^{+} \mathrm{ADCs}$ were isolated using MACS The colony-formation ability and the chondrogenetic, osteogenic, and adipogenic potentials of $\mathrm{CD} 105^{+} \mathrm{ADCs}$ were superior as compared to $\mathrm{CD}^{-105^{-}}$ADCs. This study provides theoretical and practical evidence for the identification of new stem cell-specific markers and the use of MACS for the separation and purification of ADSCs.

\section{Acknowledgements}

We thank Dr Kai Liu and Dr Qun Zhang of Shanghai Ninth People's Hospital for the adipose tissue collection; Mr. De-Min Yin and Ms. Juan-Juan Wu of Shanghai tissue engineering center for the histological experiments; the Superintendent, Dr Kai-ping Wang and the Director, Dr Xiao-chen Tian of The Second Artillery General Hospital of the Chinese People's Liberation Army for suggestions with manuscript preparation and financial support.

\section{References}

1. Heydarkhan-Hagvall S, Schenke-Layland K, Yang JQ, et al: Human adipose stem cells: a potential cell source for cardiovascular tissue engineering. Cells Tissues Organs 187: 263-274, 2008.

2. Rider DA, Dombrowski C, Sawyer AA, et al: Autocrine fibroblast growth factor 2 increases the multipotentiality of human adipose-derived mesenchymal stem cells. Stem Cells 26 : 1598-1608, 2008.
3. Baglioni S, Francalanci M, Squecco R, et al: Characterization of human adult stem-cell populations isolated from visceral and subcutaneous adipose tissue. FASEB J 23: 3494-3505, 2009.

4. Aust L, Devlin B, Foster SJ, et al: Yield of human adipose-derived adult stem cells from liposuction aspirates. Cytotherapy 6: 7-14, 2004.

5. Varma MJ, Breuls RG, Schouten TE, et al: Phenotypical and functional characterization of freshly isolated adipose tissuederived stem cells. Stem Cells Dev 16: 91-104, 2007.

6. Huang JI, Kazmi N, Durbhakula MM, Hering TM, Yoo JU and Johnstone B: Chondrogenic potential of progenitor cells derived fromhumanbonemarrowand adipose tissue: a patient-matched comparison. J Orthop Res 23: 1383-1389, 2005.

7. Im GI, Shin YW and Lee KB: Do adipose tissue-derived mesenchymal stem cells have the same osteogenic and chondrogenic potential as bone marrow-derived cells? Osteoarthritis Cartilage 13: 845-853, 2005

8. Afizah H, Yang Z, Hui JH, Ouyang HW and Lee EH: A comparison between the chondrogenic potential of human bone marrow stem cells (BMSCs) and adipose-derived stem cells (ADSCs) taken from the same donors. Tissue Eng 13: 659-666, 2007.

9. Yoshimura K, Shigeura T, Matsumoto D, et al: Characterization of freshly isolated and cultured cells derived from the fatty and fluid portions of liposuction aspirates. J Cell Physiol 208: 64-76, 2006.

10. Liu K, Zhou GD, Liu W, et al: The dependence of in vivo stable ectopic chondrogenesis by human mesenchymal stem cells on chondrogenic differentiation in vitro. Biomaterials 29: 21832192,2008

11. Hellio Le Graverand MP, Reno C and Hart DA: Influence of pregnancy on gene expression in rabbit articular cartilage. Osteoarthritis Cartilage 6: 341-350, 1998.

12. Niemeyer P, Kornacker M, Mehlhorn A, et al: Comparison of immunological properties of bone marrow stromal cells and adipose tissue-derived stem cells before and after osteogenic differentiation in vitro. Tissue Eng 13: 111-121, 2007.

13. Planat-Benard V, Silvestre JS, Cousin B, et al: Plasticity of human adipose lineage cells toward endothelial cells: physiological and therapeutic perspectives. Circulation 109: 656-663, 2004.

14. Van Dijk A, Niessen HW, Zandieh Doulabi B, Visser FC and van Milligen FJ: Differentiation of human adipose-derived stem cells towards cardiomyocytes is facilitated by laminin. Cell Tissue Res 334: 457-467, 2008.

15. Zhu Y, Liu T, Song K, Ning R, Ma X and Cui Z: ADSCs differentiated into cardiomyocytes in cardiac microenvironment. Mol Cell Biochem 324: 117-129, 2009.

16. Banas A, Teratani T, Yamamoto Y, et al: Adipose tissue-derived mesenchymal stem cells as a source of human hepatocytes. Hepatology 46: 219-228, 2007.

17. Maddox JR, Liao X, Li F and Niyibizi C: Effects of culturing on the stability of the putative murine adipose derived stem cells markers. Open Stem Cell J 1: 54-61, 2009.

18. Mitchell JB, McIntosh K, Zvonic S, et al: Immunophenotype of human adipose-derived cells: temporal changes in stromalassociated and stem cell-associated markers. Stem Cells 24: 376-385, 2006.

19. Folgiero V, Migliano E, Tedesco M, et al: Purification and characterization of adipose-derived stem cells from patients with lipoaspirate transplant. Cell Transplant 19: 1225-1235, 2010.

20. Izadpanah R, Trygg C, Patel B, Kriedt C, Dufour J, Gimble JM and Bunnell BA: Biologic properties of mesenchymal stem cells derived from bone marrow and adipose tissue. J Cell Biochem 99: 1285-1297, 2006.

21. Jiang T, Liu W, Lv W, et al: Potent in vitro chondrogenesis of CD105 enriched human adipose-derived stem cells. Biomaterials 31: 3564-3571, 2010

22. Griesche N, Luttmann W, Luttmann A, Stammermann T, Geiger H and Baer PC: A simple modification of the separation method reduces heterogeneity of adipose-derived stem cells. Cells Tissues Organs 192: 106-115, 2010.

23. Aslan H, Zilberman Y, Kandel L, et al: Osteogenic differentiation of noncultured immunoisolated bone marrow derived $\mathrm{CD} 105^{+}$ cells. Stem Cells 24: 1728-1737, 2006.

24. Arufe MC, De la Fuente A, Fuentes-Boquete I, De Toro FJ and Blanco FJ: Differentiation of synovial CD-105(+) human mesenchymal stem cells into chondrocyte-like cells through spheroid formation. J Cell Biochem 108: 145-155, 2009. 
25. Qi J, Chen A, You H, Li K, Zhang D and Guo F: Proliferation and chondrogenic differentiation of CD105-positive enriched rat synovium-derived mesenchymal stem cells in three-dimensional porous scaffolds. Biomed Mater 6: 015006, 2011.

26. Majumdar MK, Banks V, Peluso DP and Morris EA: Isolation, characterization, and chondrogenic potential of human bone marrow-derived multipotential stromal cells. J Cell Physiol 185: 98-106, 2000.

27. Ishimura D, Yamamoto N, Tajima K, Ohno A, Yamamoto Y, Washimi $\mathrm{O}$ and Yamada H: Differentiation of adipose-derived stromal vascular fraction culture cells into chondrocytes using the method of cell sorting with a mesenchymal stem cell marker. Tohoku J Exp Med 216: 149-156, 2008.
28. Cheifetz S, Bellón T, Calés C, Vera S, Bernabeu C, Massagué J and Letarte M: Endoglin is a component of the transforming growth factor-beta receptor system in human endothelial cells J Biol Chem 267: 19027-19030, 1992.

29. Johnstone B, Hering TM, Caplan AI, Goldberg VM and Yoo JU: In vitro chondrogenesis of bone marrow-derived mesenchymal progenitor cells. Exp Cell Res 238: 265-272, 1998.

30. Ito Y, Bringas P Jr, Mogharei A, Zhao J, Deng C and Chai Y: Receptor-regulated and inhibitory Smads are critical in regulating transforming growth factor beta-mediated Meckel's cartilage development. Dev Dyn 224: 69-78, 2002. 